\title{
İran Türk Değişkelerinde başar- Fiilinin Yeterlilik Fiili Olarak Kullanımı Üzerine
}

\begin{abstract}
$\ddot{\mathbf{O} z}$
İran'daki sözlü Türkçe değişkelerin yazılı Farsça değişkesiyle ve diğer yerel sözlü değişkelerle temas hâlinde olduğu bilinmektedir. Özellikle Farsça ile olan temas, yoğunluk ve derinlik bakımından diğer yerel sözlü değişkelerden ayrılmaktadır. Azerbaycan, Horasan, Türkmen, Kaşkay, Sungur, Halaç değişkeleri Günümüz İran'ında bilinen ve üzerinde çalışmalar yapılan sözlü Türkçe değişkelerdir. Bu değişkeler konuşur sayıları, coğrafi konumları, dil durumları gibi konularda farklı tipolojik görünümler sergilemektedir. Kimileri tipolojik özellikleri bakımından ciddi değişmelere uğrarken (Sungur, Kaşkay, Halaç), kimileri ise, ilk gruba göre daha az ya da yavaş bir biçimde, yazılı Farsça değişkesinden unsurlar kopyalamaktadır. Bu bildiride de İran Türk değişkelerine ait metinler taranarak başar-fillinin yeterlilik fonksiyonunda kullanılan örnekleri tespit edilecektir. Farsça tevānisten "Başarmak; yapabilmek; gücü yetmek; muktedir olmak” yeterlilik fiilinin sözlü Türkçe değişkelerin hangilerinde kopyalandı̆̆ı ve kullanım sıklı̆̆ı tespit edilerek bir coğrafi işaretleme yapılacaktır. Böylelikle kopyalamanın sözlü Türkçe değişkelerdeki yayılma alanı ve kullanım sıklığı görülmüş olacaktır.
\end{abstract}

Abdülkadir ATICI'

Anahtar kelimeler: İran, İran Türk değişkeleri, kopyalama, başar- fiili.

\section{On the Use of Verb başar- as the Use of Potencial in Turkish Dialects of Iran}

\begin{abstract}
It is known that oral Turkish dialects in Iran are in contact with written Persian dialect and other local oral dialects. Especially contact with Persian is different from other local oral dialects in terms of intensity and depth. Azerbaycan, Horasan, Türkmen, Kaşkay, Sungur, Halaç dialects oral Turkish dialects known and worked on in today's Iran. These dialects display different typological appearances on issues such as number of conversations, geographical locations, language situations. While some are undergoing serious changes in their typological characteristics (Sungur, Kaşkay, Halaç), others are copying elements from the written Persian dialect in a less or slower manner than the first group. In this report, texts of Turkish dialects of Iran will be searched and examples of successes used in the sufficiency function will be determined. Persian تو انستن tevānisten "Achievement; To do; afford; being able to be competent "is copied in the oral Turkish dialects and the usage frequency is determined and a geographical mark will be made. Thus, copying will have seen the spreading area and usage frequency of oral Turkish dialects.
\end{abstract}

Key words: İranian, Turkish dialects of Iran, copying, verb of başar-.

Dr. Öğr. Üyesi, Kırklareli Úniversitesi, Fen Edebiyat Fakültesi, Çağdaş Türk Lehçeleri ve Edebiyatları Bölümü, tanabayy@hotmail.com, [Makale kayit tarihi: 12.6.2018-kabul tarihi:15.8.2018] 


\section{Giriş}

İran'da Azerbaycan, Horasan, Türkmen, Sungur, Kaşkay ve Halaç gibi çeşitli Türkçe değişkelerin² bulunduğu bilinmektedir. Bu değişkelerden Halaç değişkesi bünyesinde barındırdığı arkaik unsurlar sebebiyle diğer Türkçe değişkelerden ayrlmaktadır. Horasan ve Türkmen değişkeleri de İran'ın kuzeydoğusunda Azerbaycan ve Türkmen değişkeleri arasında bir geçiş değişkesi görünümü sergilemektedir. Kaşkay değişkesi mevcut Türkçe değişkeler arasında en güneyde bulunan ve dil tipolojisi bakımından en fazla değişmeye uğrayan değişke olarak karşımıza çıkmaktadır. Kirmanşah eyaletinin doğusunda konuşulan Sungur değişkesi ise Kaşkay değişkesi kadar uzakta olmamasına rağmen etrafını çeviren (yazılı Farsça değişkesi, Kürtçe, Lorca ve Lekçe gibi sözlü değişkeler) farklı değişkeler sebebiyle tipolojik açıdan farklılaşan bir diğer değişkedir. Azerbaycan değişkesi ise Batı Azerbaycan, Doğu Azerbaycan, Erdebil, Zencan, Kazvin, Hemedan eyaletlerini içine alan ve konuşur sayısı bakımından en büyük kitleyi oluşturan değişke grubudur.

Görüleceği üzere Türkçe değiş̧keler, İran'ın kuzeybatısında yoğunlaşmakta ama bununla birlikte İran’ın birçok yerinde de farklı yoğunlukta temsil edilmektedir. Azerbaycan değişkesi yüksek konuşur oranı, günlük hayatta Türkçe değişkelerin işlevsel oluşu sebebiyle diğer değişkelerden daha avantajlı durumdadır. Konuşur oranının azalması, günlük hayatta Türkçe değişkelerin işlevsizleşmesi, farklı dillerle olan temasın artması gibi sebeplerle Azerbaycan değişkesi dışında kalan değişkeler dezavantajlı değişkeler olarak karşımıza çıkmaktadır. Ses, şekil, cümle yapısı ve sözvarlığına kadar hemen her alanda dil temasları sonucu karşımıza çıkan tipolojik değişmeler dezavantajlı değişkelerde daha fazla görülmektedir. Bu anlamda İran'daki Türkçe değişkelerde dil teması sonucu Farsçadan kopyalanmış3 olan Peh. tevānisten (توانسن) "başarmak; yapabilmek; muktedir olmak, güçlü olmak" (Kanar 2010: 520) fiilinin Türkçe değişkelerde yeterlilik fiili olarak kullanımına ait örnekler verilecek ve bu kopyalama örneklerinin yukarıda belirtmiş olduğumuz değişkelerdeki kullanım sıklı̆ına bakılacaktır. Böylelikle kopyalama örneklerinin hangi değişkelerde hangi seviyede olduğu tespit edilmiş olacaktır.

\section{Yeterlilik Kategorisi}

Yeterlilik, konuşurun bir eylemin olup olmayacağ (Korkmaz 2003: 172) konusunda eylemi gerçekleştirenin potansiyeline bağlı olarak sübjektif bir biçimde yaklaşımını ifade ettiği bir kiplik kategoridir. Tüm zaman ve kip işaretleyicileriyle kullanılması sebebiyle çekim morfolojisinin, cümle içerisinde çeşitli anlamlar ifade etmesi sebebiyle de semantiğin araştırma alanı içine girmektedir (Mehmet 2007: 81). Yeterlilik kurulumu, kullanım amacına göre yeterlilik4, olasllk5, izin ${ }^{6}$, ve rica gibi $^{4}$ çeşitli işlevler üstlenebilmektedir. Burada hangi kiplik anlamın kullanılacağı konuşurun olaya yaklaşımıyla belirlenmektedir8. Ayrıca yeterlilik kurulumunda yeterliliği söz dizimi ifade ederken yetersizlik ifadesi biçim bilgisi düzleminde gerçekleşmektedir (Karaağaç 2013: 867).

\subsection{Türkçede Yeterlilik}

\footnotetext{
Bu çalışmada kullanılan değişke terimi; dil, lehçe, şive, ağız vd.ni birlikte ifade etmektedir Eker 2008: 91.

$3 \quad$ Kopyalama, Lars Johanson tarafından 'yabancı kodların kopyalarının ekleme için gerekli morfosentaktik çerçeveyi sağlamış biçimde yerli dile eklenmesi' olarak tanımlanmıştır (2007: 29). Türkçeden hareketle ortaya atılan bu kuram başka dillerdeki benzer durumları da açıklamak için kullanılabilmektedir (2007: 28-37). Kopyalama üzerine detaylı bilgi için bk. Johanson 1998a: 325-337, 1998b: 81-125, 2002, 2005: 3-31, 2006, 2007.

Ör. Çok güzel resim yapabilirim.

Ör. Çok hızlı araba kullanıyor, kaza yapabilir.

Or. Sen de benimle gelebilirsin.

Ör. Müziğin sesini biraz kısabilir misin?

Yeterlilik fiilinin kiplik anlamları üzerine detaylı bilgi için bk. Kerimoğlu 2011: 84-85, Korkmaz 1959 107-124.
} 
Türkiye Türkçesinde yeterlilik fiilinin olumlusu fiil+zarf-fiil+bil-+zaman+şahıs diziliminden oluşurken olumsuzunda/yetersizlikte ise fiil+AmA+zaman+şahıs dizilimi söz konusudur. Türkçenin tarihsel dönemlerine bakıldığında yeterlilik fiili için $u$, al-, bil- fiillerinin kullanıldığı görülmektedir. Köktürk döneminde yeterlilik fiili olarak çoğunlukla $u$ - fiili kullanılmış, Karahanlı döneminde ise $u$ - fiili dilbilgiselleşerek yardımcı fiil durumuna geçmiştir (Korkmaz 1959: 109-110). Eski Uygur Türkçesi döneminde -gAlI+bol- yapısı da yeterlilik fonksiyonunda kullanışmıştır (Gabain 2007: 88). Harezm Türkçesi (Eckmann 2003: 25) döneminde $u$-, bil- ve al- fiilleri kullanılırken Çağatay Türkçesi döneminde yetersizlik fonsiyonunda $u$ - fiili kullanımdan kalmış ve -A+al-/bil- birleşiminin kullanım frekansı yükselmiştir (Eckmann 2003: 144). Görüleceği gibi Eski Türkçe döneminde ağırlıklı olarak yeterlilik fonksiyonunda $u$ - fiili kullanılırken sonraki dönemlerde al-, bil- fiilleri kullanılmaya başlamıştır9.

Günümüz yazılı Türk değişkelerine bakıldığında ağırlıklı olarak yeterlilik fiili için bil- ve al- fiilerinin kullanıldığı görülmektedir. Yazılı Kazak, Nogay, Tatar, Kırım-Tatar10 ve Tuva değişkelerinde ise ol- fiili de yeterlilik fonksiyonunda kullanılmaktadır ${ }^{11}$ (Ersoy 2016: 86-87).

İran'daki sözlü Türkçe değişkelere baktığımızda birazdan tanıklayacağımız kopyalama örneklerinin yanı sıra Genel Türkçede olduğu gibi bil-, Tebriz değişkesindeki eliye bil- (Kıral 2001: 84), Urmiye değişkesindeki (Doğan 2010: 323) mak ol- şeklindeki yapılarla yeterlilik çekimi oluşturulmaktadır. Olumsuzluk/yetersizlik çekimininde ise -ebilme-, -AlmA-, -AmmA-, AnmA-, -AmA- yapıları kullanılmaktadır ${ }^{12}$.

\subsection{Farsçada Yeterlilik}

Farsçada yeterlilik çekimi توانستن - توان tevānisten - tevān "muktedir olmak" fiili ile ve iki şekilde yapılmaktadır. Bunlar:

a. تو انستن tevānisten fiilinin istenilen zamanının sonuna esas fiilin geçmiş zaman çekimi getirilerek, تو انم رفت tevānem reft "gidebilirim", مى توانم رفت mitevānem reft "gidebiliyorum", توانستم رفت tevānistem reft "gidebildim".

b. توانستن tevānisten fiilinin istenilen zamanının sonuna esas fiilin istek çekimi getirilerek yapılmaktadır. tevānem berevem "gidebilirim", توانم بروم تو توانم بروم mitevānem berevem "gidebiliyorum", توانتم بروم tevānistem berevem "gidebildim".

Yeterlilik çekiminin olumsuzunda ise توانستن tevānisten fiilinin önüne olumsuzluk işaretleyicisi olan ن(ن) ne getirilmektedir.

Tarihsel dönemde yeterlilik ve yetersizlik fiillerine ait tablo için bk. Ersoy 2016: 86.

Kırım-Tatar için ayrıca bk. Yüksel 2001: 417-425.

Günümüz yazılı Türk değisskelerinde yeterlilik ve yetersizlik fiillerine ait tablo için bk. Ersoy 2016: 86-87.

İran'daki sözlü Türkçe değişkelerdeki yeterlilik fiilinin kullanımı üzerine detaylı bilgi için bk. Gökdağ 2016: 201-207, Kıral 2005: 288-291. 


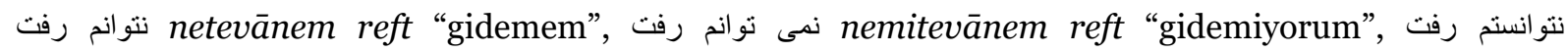
netevānistem reft "gidemedim", نتوانم بروم netevānem berevem "gidemem", نمى تونى nemitevānem berevem "gidemiyorum” نتوانستم بروم, netevānistem berevem "gidemedim” (Öztürk 2007: 50; 79-84)13.

\section{Yeterlilik Fonksiyonunda başar- Fiili}

Yukarıda da belirtildiği gibi Farsçada yeterlilik tevānisten fiilin istenilen zamanda çekimlenmiş hâli + şahıs eki+ esas fiilin geçmiş zamanda ya da istek çekiminde çekimlenmesi ile oluşmaktadır. İran Türk değişkelerinde de tıpkı yazılı Farsça değişkesinde olduğu gibi başar-fiili+zaman+şahıs+esas fiil+zaman+şahıs biçiminde gerçekleşmektedir. Sözlü Türkçe değişkeler yeterlilik çekiminde zarf fiil+al-/bil- gibi yapıların yanı sıra Farsçadan kopyaladıkları başar- fiilini kullanmaktadırlar. Yeterlilik bildiriminin olumsuzunda/yetersizlikte ise olumsuzluk eki hemen başar- fiilinden sonra kullanılmaktadır.

tevānistem reft/berevem "gidebildim"

netevānem reft/berevem "gidemem" *başardım gidem "gidebildim".

*başarmerem gidem "gidemem".
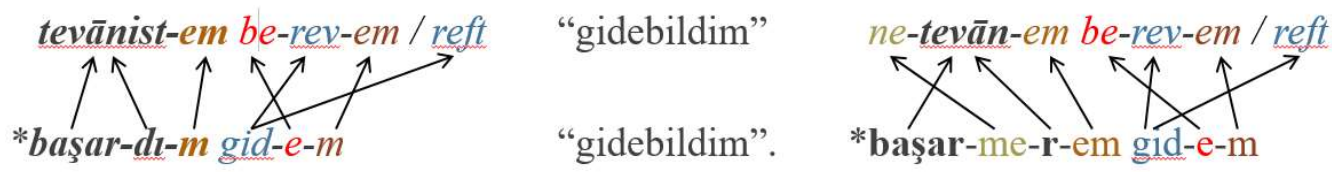

"gidemem"

"gidemem"

Yukarıdaki örnekten de anlaşılacağı üzere sözlü Türkçe değişkeler yeterlilik çekiminde fiil+istenilen zaman eki+şahıs eki+esas fiil+istek eki+şahıs eki biçiminde çekimi gerçekleştirmektedir. Sınırlı sayıda örnekte esas fiilden sonra emir eki bulunsa da genel olarak yeterlilik çekiminde esas fiil istek ekiyle çekime girmektedir. Bu da Farsça yeterlilik çekiminin ikinci şeklinden kopyalandığını göstermektedir.

\subsection{Azerbaycan Değişkesi Kopyalama Örnekleri}

Gerek alan araştırmalarımız sırasında gerekse de metin taramalarında elde ettiğimiz kopyalama örneklerine bakacak olursak Azerbaycan değişke grubunda Hemedan değişkesi kopyalama örneklerinin çokluğu bakımından diğer değişkelerden ayrılmaktadır. Batı Azerbaycan (Salmas ve Urmiye değişkelerinde sınırlı sayıda Hoy değişkesinde hiç yok), Doğu Azerbaycan ve Zencan değişkelerinde sınırlı sayıda örnek tespit edilirken Erdebil (Karini 2009; Karini 2012) değiş̧kesinde yeterlilik fonksiyonunda kullanılmış başar- fiiline ait örnek tespit edilememiştir.

Batı Azerbaycan değişkesi üzerine yaptığımız taramalarda toplamda altı örnek tespit edilmiştir. Bu kopyalama örneklerinin dört tanesi Salmas, iki tanesi ise Urmiye değişkesine aittir. Hoy (Özkaya 2013) değişkesine ait ise kopyalama örneği tespit edilememiştir.

sen héş zat başarmısan? "Sen hiçbir şey yapamiyor musun? (Gökdağ 2006: 175), feş toxumax başarar̆ "Halı dokuyabilir.” (Gökdağ 2006: 239), ġolay başarram "Kolay yapabilirim.” (Gökdağ 2006: 239), her kes başarır, gelsin, mene yorgan tiĥsin "Gelebilen herkes gelsin, bana yorgan diksin." (Gökdağ 2006: 243).

13 Ayrıca tevānisten (توانستن) fiilinin bütün şahıs ve zamanlarının çekimi için bk. Öztürk 2007: 79-85. 
biz başarmırıx “Biz yapamıyoruz” (Doğan 2010: 376), oxumax başarırdı “Okuyabilirdi.” (Doğan 2010: 489).

Doğu Azerbaycan değişkesinde de kopyalama örnekleri sınırlı sayıda da olsa tespit edilmiştir.

mændæ bafa:jam "Ben de yapabilirim." (Bicbabaei 2012: 540), mæn søhbæt bafajmanam "Ben konuşamam.” (Bicbabaei 2012: 567), søhbæt bafajmijam "Konuşamıyorum.” (Bicbabaei 2012: 568), mæn nayit bafajmanam "Hikâye anlatamam/bilmiyorum." (Bicbabaei 2012: 572), savadim joxdu amma mæsælæm sidzillimi bafajjam "Okuma yazmam yok ama adımı soyadımı okuyup yazabiliyorum." (Bicbabaei 2012: 572), ota: bafajjam "Onları yapabiliyorum." (Bicbabaei 2012: 572), æzbæjdæn bafajjam "Ezberden yapabiliyorum.” (Bicbabaei 2012: 572), ax bij zadi jæræh bafarasan dijæsæn "Bir şeyler söyleyebilirsin, anlatabilirsin herhalde.” (Bicbabaei 2012: 738).

danışmağıvı başarmazdın "Konuşamazdın." (Özdamar 2015: 54), Sən sazın pərdəsin tutmağın və danışı̆̆ıı başarmazdın "Sen saz çalamaz, konuşamazdın/söyleyemezdin.” (Özdamar 2015: 55).

Erdebil değişkesinde taranan metinlerde (Gülmez 2008; Karini 2009; Karini 2012) yeterlilik fonksiyonunda başar- fiiline ait örnek tespit edilememiştir.

Zencan değişkesinde de üç örnekte başar- fiili yeterlilik fonksiyonunda kullanılmıştır.

hesap zat başarram "Hesap filan yapabilirim (Rezaei 2015: 278), didi baba a néce başartr "O (bunu) nasıl yapabilir, dedi." (Rezaei 2015: 283), bị̣ zat başą̧mırıx kí diyek "Bir şey yapamıyoruz ki söyleyelim." (Rezaei 2015: 351).

Buraya kadar olan ve Azerbaycan değişke grubu içinde değerlendirdiğimiz değişkeler görüleceği üzere sınırlı sayıda kopyalama örneklerine sahiptirler. Fakat birazdan örneklerini sıralayacağımız Hemedan değişkesi Azerbaycan değişke grubu içinde yer almasına rağmen kopyalama örneklerinin çokluğu bakımından diğer değişkelerden bariz bir şekilde ayrılmaktadır.

Hemedan değişkesinde yeterlilik fonksiyonunda kullanılan başar- fiiline ait tespit edilen örnekler şu şekildedir.

hiç kes başarmadı kapını aça "Kimse kapıyı açamadı." (Gün 2016: 246), her ne başardı buna hürmet eyledi "Yapabileceği her şeyi yaptı." (Gün 2016: 254), başarmıyan pişiren? "Pişiremez misin? (Gün 2016: 254), o atı hiç kes başarabilmiri "O atı kimse dizginleyemiyor." (Gün 2016: 264), başarmaz danışa "Konuşamaz" (Gün 2016: 302), başarmazdım çalam "(müzik aleti) Çalamazdım” (Gün 2016: 336), başarmam diyem "Söyleyemem" (Gün 2016: 342), eger başarmadım işare eyleginen "Eğer yapamazsam söyle” (Gün 2016: 343), başarmadı yoğ diye "Yok, diyemedi” (Gün 2016: 348), kim başartr bunu verir ona "Kim bunu ona verebilir" (Gün 2016: 349), başarabilmek cevap verek "Cevap veremiyoruz" (Gün 2016: 396), bir zad başarmırdı diye "Bir şey söyleyemiyordu” (Gün 2016: 418), başarmaz düşman menimle dayana "Düşman benimle baş edemez" (Gün 2016: 450), hiç kes başarmaz menim elimden ala "Kimse benim elimden alamaz" (Gün 2016: 519), sen menimle başarmey "Sen benimle baş edemezsin" (Gün 2016: 555), didi kardaş başartray çalay "(müzik aleti) Çalabilirim kardeşim, dedi” (Gün 2016: 564), seniynen hiç kes başarmaz "Kimse seninle baş edemez" (Gün 2016: 566), şeir başaririk "Şiir söyleyebiliriz, okuyabiliriz" (Gün 2016: 709), eger başarebilmedik kaçak sen bir söz dimen "Eğer kurtulamazsak bir şey söyleme" (Gün 2016: 725), yoldaşın başarmayıp Şahtaş Hanmım'a danışa “Arkadaşın Şahtaş Hanımla konuşamamış” (Gün 2016: 910), başarmazla sana yalan 
danışala "Sana yalan söyleyemezler" (Gün 2016: 953), başarabilerdim götürem kaçam buradan seni "Seni buradan götürebilirdim, kaçırabilirdim" (Gün 2016: 1028), men başarabilmem burada şahlı̆ eyliyem "Ben burada Şahlık yapamam" (Gün 2016: 1062), indi başarmıram da danışam "Artık konuşamıyorum" (Gün 2016: 1134), quz başarmaz diye men gitmirem "Kız gitmiyorum, diyemez" (Gün 2016: 1136), men başarmam alam "Ben alamam" (Gün 2016: 1152), indi men bunu yola sallam ama sen başarabilmey "Şimdi ben bunu (dedeyi) uğurlayayım ama sen gidemezsin” (Gün 2016: 1185), kim başarardı déye menim garnım dolídı "Kim karnım tok diyebilirdi" (Pehlivan 2011: 183), bizler başarmeg "Biz yapamayı/yapamıyoruz." (Pehlivan 2011: 323), yetmişe de başarmam sayam "Yetmişe kadar sayamam." (Pehlivan 2011: 344), men başartram "Ben yapabilirim.”( Pehlivan 2011: 345), oğlana déyer her ne başartrın yi “Çocuğa ne kadar yiyebilirsen ye, diyor." (Pehlivan 2011: 195).

\section{2. Kaşkay Değişkesi Kopyalama Örnekleri}

Kaşkay değişkesine ait metinlerinde ( Ma'zun 2016; Çelik 1997, 2014; Yaghoobi 2011; Gündüz 2010; Aghdam 2009, Csato 2005: 271-283, 2006: 209-225) kopyalama örnekleri beklenin aksine toplam dört örnekte tespit edilebilmiştir. Yeni yayınlar olan Ataizi (2017) ve Doulatabadi’nin (2017) çalışmalarında ise toplamda yirmiye yakın kopyalama örneği tespit edilmiştir.

başaram néçäsin taniyäm "Birkaçını tanıyabilirim" (Ataizi 2017: 268), daşaram diyem "Söyleyebilirim" (Ataizi 2017, 269), siz nicäki başaräñ bu işi göräñ "Bakalım bu işi nasıl yapabileceksiniz" (Ataizi 2017: 279), ora çoh gözäl yerdir başaräñiz gidäñiz "Orası çok güzel bir yerdir, gidebilirseniz gidin" (Ataizi 2017: 277, Doulatabadi 2017:37), başaräñ gideñ "gidebilirsin/gidebilirsen” (Ataizi 2017: 277), başarer bir noḩhuşligi huub edä "Bir seyit bir nahoşuluğu hoş/iyi yapabilir" (Ataizi 2017: 279), başarermiş şäfa verä "Şifa verebilirmiş" (Ataizi 2017: 279), bundan artŏh başarérmişeg iş göreg "Bundan sonra çalışabiliriz" (Ataizi 2017: 254), başarilärmiş şähr içindä olalar "Şehirde olabiliyorlarmış/durabiliyorlarmış" (Ataizi 2017: 295), başarir sabet edä "Sebat edebilir" (Ataizi 2017: 282), fägät biz Sefäviyä’dän sonra başariräk deyäk kimäk "Sadece Safeviden sonra kim olduğumuzu söyleyebiliyoruz" (Ataizi 2017: 295), Ahı biz başaräm deyäm Türkiyäyinän indiké däk értibat yohumuzudu "Türkiye ile şimdiki gibi irtibatımız olmadığını söyeleyebilirim" (Ataizi 2017: 264), Säcugiilär bulâr çoh başaräm deyäm beigig hükümätläridi "Selçukluların çok büyük devletler olduğunu söyleyebilirim" (Ataizi 2017: 266), hänüz başarmamişek bunnârl araliyäk ké göräk "Henüz bunları araştırıp bulamamışız" (Ataizi 2017: 295), başarmeräk dilimizä gatäk "Henüz dilimize sokamamışız" (Ataizi 2017: 295), ta munnar başarmeyälär danŏşälär "Henüz konuşamadılar" (Ataizi 2017: 276), başarmışam färhängimi héfz edäm "Kültürümü koruyabildim" (Ataizi 2017: 296), eger başardıng gideng bir kilitdir, div mekannınna div eline, eger bunu getırding men kızımı verem belenge "Eğer devin evine gidip anahtarı bana getirebilirsen kızımı sana veririm." (Çelik 2014: 50), eger başardıng meni beyninneng aparang "Yapabilirsen/gücün yeterse beni öldür." (Çelik 2014: 51), başarmam hökmüni inkār èyleyem "Hükmünü inkâr edemem" (Yaghoobi 2011: 346), sän bašayiräy gedäy "Gidebilirsin." (Kiral 2005: 290-291).

\subsection{Halaç Değişkesi Kopyalama Örnekleri}

Halaç değişkesi üzerine yapılan metin taramalarında (Darabadi 2017, Doerfer 1988, 1997, Cemrasi 2009, 2013, 2015, 2015a) başar- fiiline ait kopyalama örnekleri tespit edilememiştir.

\section{4. Sungur Değişkesi Kopyalama Örnekleri}

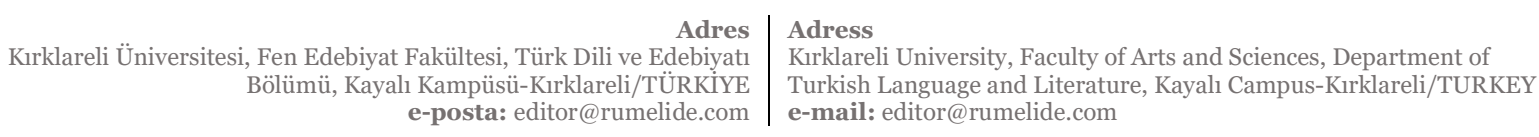


Sungur değişkesinde yeterlilik fonksiyonunda kullanılan başar-fiiline ait örnek sayısı oldukça fazladır. Alan araştırmamız sırasında kaynak kişilerle yaptığımız yüzyüze görüşmelerde bu kopyalama örneklerinin her şahısta kullanıldığı tespit edilmiştir.

başarmerem farsî "Farsça konuşamıyorum." (Atıcı 2015: 213), düşmişem başarmerem "Yaşlanmışım (artık) yapamıyorum." (Atıcı 2015: 225), başarise neçe bendini ohiyåvise bılemiz içi "Birkaç bendini bizim için okuyabilir misin?" (Atıcı 2015: 253), başermezsız şéri áruzi diyesız "Aruzla şiir okuyamazsınız/yazamazsınız." (Atıcı 2015: 256), başardah ıstanbulį örgenah "İstanbul Türkçesi öğrenebiliriz." (Atıcı 2015: 265), başardaḩ azerbaycanįni keşey danışah "Güzel bir şekilde Azerbaycan Türkçesi konuşabiliriz." (Atıcı 2015: 265), başermerem taş çalmag "Taş çalamam.” (Atıcı 2015: 272), başardem yiyem "Yiyebilirim.", başarise yiyese "Yiyebilirsin.", başari yiye "Yiyebilir.", başardaћ yiyaћ "Yiyebiliriz.", başarisız yiyesız "Yiyebilirsiniz.", basarılle yiyelle "Yiyebilirler." (Atıc 2015: 279), başardem yazem "Yazabilirim.", başarise yazese "Yazabilirsin", başari yaze "Yazabilir", başardah yazah "Yazabiliriz", başarisız yazesız "Yazabilirsiniz.", başarılle yazelle "Yazabilirler." (Atıcı 2015: 279), dilim kali kıçım altine, başarmerem "Dilim ayağı mının altında kaldı (dilim tutuldu), konuşamıyorum (Atıcı 2015: 289), eger bi arem başarmeydi, mutercım geleydi haí_iyliyeydi "Eğer biri konuşamasaydı (Farsça bilmeseydi), mütercim gelip hallederdi (tercüme yapardı) (Atıcı 2015: 294), eger başardu ge mehsūsen hoşum gelov "Gelebilirsen, çok sevinirim." (Atıcı 2015: 309), başermezle gelelle "Gelemezler." (Atıcı 2015: 327), başermerem gelem "Gelemem." (Atıcı 2015: 327), bız başarmerah diyah "Biz söyleyemiyoruz." (Atıcı 2015: 333).

\section{5. Horasan-Türkmen Değişkesi Kopyalama Örnekleri}

Türkmen değişkesi (Yıldırım 2015, Ceylan 2010, ) üzerine yapılan taramalarda başar- fiiline ait kopyalama örnekleri tespit edilememiştir.

Horasan değişkesinde ise Hemedan ve Sungur değişkelerinde olduğu gibi kopyalama örnekleri oldukça fazladir.

biz bịrnıni başarmịyéy bịr älimizdä äzey "Biz birini (dahi) bir elimizle ezemiyoruz” (Tulu 2009: 38), dievä här nämä edịyällän, başarmịällän "Devler ne yapsalar, başaramiyorlar." (Tulu 2009: 38), tşärtimi başarmadipiz äncām (beräniz) "Şartımı yerine getiremediniz." (Tulu 2009: 38), hạr nämädịyä, başarmịä tŏrsın “(Karga) her ne yapsa, uçamaz/duramaz” (Tulu 2009: 44), indi här nämä edärdi ki muni ärxäläsin, başarmạsdi ärxäläsin "Ancak sırtına almak için ne yaptıysa da sırtına alamadı." (Tulu 2009: 77), başarmịyä gätirsin “Getiremiyor.” (Tulu 2009: 77), näġana başarsän belä bịr ịs edäy "Nasıl böyle bir iş yapabilirsin." (Tulu 2009: 89), indi başarmịyäm bŏlạri ġozin ịçinä salịm, erțim èz mämläkätimä "Şimdi bunları cevizin içine geri koyup kendi memleketime götüremiyorum." (Tulu 2009: 97), bŏ xatin muna dedi ki hiç qorxmạ, indi gụl mundạ başarmịyä gälsin "Kadın ona dedi ki: "Hiç korkma şimdi dev buraya gelemez." (Tulu 2009: 99), o vạxt başarräy, muniynän izdivāc edäy

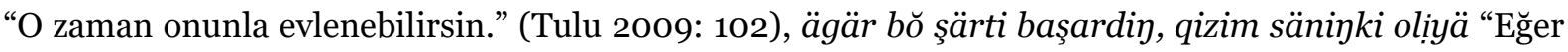

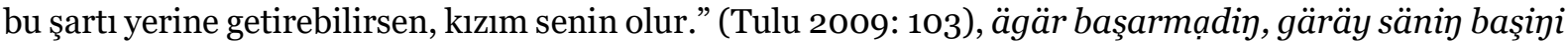
käsäy “Eğer getiremezsen, senin başını keserim!” (Tulu 2009: 103), här kim atiynän başardi (h)ōziy o tạrậinnän siçiräsin obịr täräfinä, şu haldä ki siçirịyä, padişanịn qizi bịr almạ taşlịä "Kim atıla hendeğin o yanından bu yanına atlayabilirse, bu şekilde sıçrarsa, padişahın kızı (ona) bir elma atacak." (Tulu 2009: 110), ägär bŏ başarsin bŏ almạni tutsin, bŏ qiz onki olịä "Eğer bu elmayı tutabilirse, /bu/ kiz onun olacak." (Tulu 2009: 110), hiç iş başarmịyäy edäy "Hiçbir iş yapamıoruz." (Tulu 2009: 111),

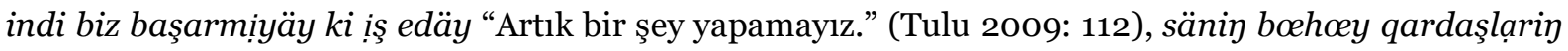


ki başarmạdilän bịr iş "Büyük kardeşlerin bir şey yapamadılar." (Tulu 2009: 122), başarmịyäm yol gidịm "Yürüyemem.” (Tulu 2009: 122), başarmịyä yol giDsin "Yürüyemez." (Tulu 2009: 122), dedi indi başarịyän yol gidäy "Dedi: Artık yürüyebilirsin.” (Tulu 2009: 122), sän başarmịyäy mänê darä çäkäy "Sen beni asamazsın.” (Tulu 2009: 135), tavịlädä bir teylå $\gamma$ vårdi, manị hiş kim båşärmị tavlänị işgini åşsın “Ahırda bir tay vardır, fakat hiç kimse ahırın kapısını açamıyor.” (Özden 2014: 142), ä’gär şå özü, şåzådä özü båşärär minị işgini åşsin, gälsin géssin, minị işgini åşsin "Eğer şehzadenin kendisi bunun

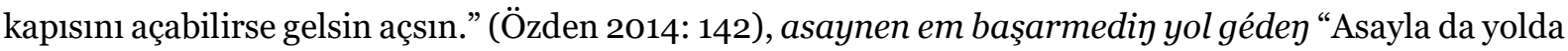
gidemedin.” (Doğan 2016: 106), emma genam başarmesdi otırsın "Ama yine de oturamazdı." (Doğan 2016: 86), başarmesdi biraz êzini ġıssın "Kendine baskı yapamazdı.” (Doğan 2016: 86).

\section{Sonuç}

İranî değişkeler14 ile sözlü Türkçe değişkelerin siyasi, sosyal ve kültürel açıdan uzun süreli bir temas içinde oldukları bilinmektedir. Sembiyotik ilişki olarak adlandırılan bu durum şüphesiz iki ayrı genetik kökenden gelişen Türkçe ve Farsçayı tipolojik açıdan birbirine benzer diller hâline getirmiştir. Uzun süreli bu etkileşim her iki dilin de çekici özelliklerini bir diğerine kopyalaması şeklinde cereyan etmiştir. Bu bildiride de tevānisten (توانسن) fiilinin İran'daki sözlü Türkçe değiş̧kelerdeki kopyalama örnekleri taranmıştır. Böylelikle kopyalama örneklerinin sözlü Türkçe değişkelerdeki durumu tespit edilmiştir.

Buna göre İran'daki sayı bakımından en büyük değişke grubunu oluşturan Azerbaycan değişkesinde Hemedan değişkesi hariç kopyalama örneklerinin sınırlı sayıda olduğu tespit edilmiştir. Bu durum Türk nüfusunun azaldığı ya da sınır teşkil ettiği bölgelerde yazılı Farsça değişkesinin sözlü Türkçe değişkeler üzerinde daha etkili olduğunu göstermektedir. Bu açıdan bakıldığında Hemedan değişkesindeki kopyalama örneklerinin fazlalığı görüşümüzü desteklemektedir.

Kaşkay değişkesi normalde tipolojik açıdan en fazla değişime uğramış değişkeler arasındadır ve normalde konumuz olan kopyalama öreklerini de fazlasıyla kopyalamış olması beklenmektedir. Fakat Kaşkay metinleri üzerinde yaptığımız taramalarda, Ataizi (2017) hariç, kopyalama örnekleri sınırlı sayıda tespit edilebilmiştir.

Halaç değişkesi de Kaşkay değişkesinde olduğu gibi dil tipolojisi bakımından oldukça değişime uğramış ve kopyalama örneklerini fazlaca görmeyi öngördüğümüz bir değişkedir. Fakat yapılan taramalarda başar- fiili ile ilgili kopyalama örnekleri tespit edilememiştir.

Bir diğer tipolojik açıdan farklılaşmış değişke ise Sungur değişkesidir. Alan araştırmamız sırasında adı geçen kopyalama örnekleri üzerine özel derlemeler yaptığımız için her şahısta kopyalama örnekleri tarafımızca tespit edilmiştir.

İran'ın kuzeydoğusunda yer alan Horasan değişkesi de Sungur ve Hemedan değişkeleriyle birlikte kopyalama örneklerinin fazlaca bulunduğu bir diğer değişke olarak karşımıza çıkmaktadır. Horasan değişkesinin yanı sıra Türkmen değişkesinde kopyalama örnekleri tespit edilememiştir. Horasan değişkesinde kopyalama örnekleri oldukça fazlayken Türkmen değişkesinde kopyalama örneğinin tespit edilememiş olmasına temkinli yaklaşmak ve Türkmen değişkesi üzerine daha detaylı derlemeler yapıldıktan sonra tekrar gözden geçirmek gerekmektedir. Aksi takdirde aynı havzada bulunan ve

14 İranî diller (değişkeler) terimi hakkında bk. Eker 2010: 321, 2013: 445. 
birbirine yakın dilsel özellikler gösteren bu iki değişke arasındaki kopyalama farklılığının izahı ya güç olacaktır ya da mantıklı bir sebebi bulunacaktır.

Bir bütün olarak değerlendirme yapacak olursak İran'ın kuzeybatısı olarak işaretleyebileceğimiz Azerbaycan değişke grubu Hemedan eyaleti hariç kopyalama örneklerinin azlığı bakımından diğer değişkelerden ayrılmaktadır. Büyük kitleden ${ }^{15}$ uzak $^{16}$ ya da kıyısında ${ }^{17}$ olan sözlü Türkçe değişkeler ise kopyalama örneklerinin fazlalığı sebebiyle ayrı bir blok oluşturmaktadır.

\section{Kaynakça}

Aghdam, A., A., (2009), Kaşkay Türklerinde Atasözleri, İzmir: Ege Üniversitesi Sosyal Bilimler Enstitüsü Yayımlanmamış Yüksek Lisans Tezi.

Ataizi, E., D., (20179, Kaşkay Türklerinin Dili, Ankara: TDK Yayınları.

Atıcı, A., (2015), Sungur Türkçesi, Konya: Eğitim Yayınevi.

Bicbabaei, B., (2012), Melekan (Melek Kendi) İli Ă̆zl, Ankara: Ankara Üniversitesi Sosyal Bilimler Enstitüsü Çağdaş Türk Lehçeleri ve Edebiyatları Ana Bilim Dalı Yayımlanmamış Doktora Tezi.

Cemrasi, A., A., (2009), Karşu Balukka Selam, Tahran: Endişe-yi Nov.

Cemrasi, A., A., (2013), Tülkü Matal, Tahran: Neşr-i Tekdireht.

Cemrasi, A., A., (2015), Hacı Tülkü Matal, Bahar.

Cemrasi, A., A., (2015a), Gül Senüber Destanı, Tahran: Neşr-i Tekdireht.

Ceylan, M., (2010), İran Türkmencesinde Yapım Ekleri (Farsça-Türkmence Gazi Sözlüğü Üzerinden Bir İnceleme), Kırıkkale: Kırıkkale Üniversitesi Sosyal Bilimler Enstitüsü Yayımlanmamış Yüksek Lisans Tezi.

Csato, E., A., (2005), "On Copying in Kashkay", LinguisticCconvergence and Areal Diffusion: Case Studies from Iranian, Semitic and Turkic. (Ed. Eva A. CSATO, Bo ISAKSSON, Carina JAHANI), London: Routledge Curzon, S. 271-283.

Csato, E., A., (2006), "Gunnar Jarring's Kashkay Materials", Turkic-Iranian Contact Areas. Historical and Linguistic Aspects, (Ed. Lars JOHANSON, Christiane BULUT), Wiesbaden: Harrassowitz, S. 209-225.

Çelik, M., (1997), Kaşgay Türkçesi (Giriş, İnceleme, Metinler, Sözlük), Malatya: Üniversitesi Sosyal Bilimler Enstitüsü, Yayımlanmamış Doktora Tezi.

Çelik, M., (2014), Kaşkay Türkçesi Metinleri, Ankara: Gece Kitaplı̆̆ı Yayınları.

Darabadi, M., D., (2017), Halaçça: Belgeleme ve Dilbilgisi Çalışması, Ankara: Hacettepe Üniversitesi Sosyal Bilimler Enstitüsü Yayımlanmamış Yüksek Lisans Tezi.

Doerfer, G., (1988), Grammatik des Chaladsch, Wiesbaden: German Edition.

Doerfer, G., (1997), Khalaj Materials, Bloomington: İndiana University.

Doğan, T., (2010), Urmiye Ağızları, Kırıkkale: Kırıkkale Üniversitesi Sosyal Bilimler Enstitüsü Yayımlanmamış Doktora Tezi.

Doğan, T., (2016), Geşeng Ginle, Ankara: Akçağ Yayınları.

Doğan, T., (2017), Horasan Türkçesi Metinleri, Konya: Palet Yayınları.

${ }_{15}$ Büyük kitle olarak Türklerin sayıca kalabalık olduğu Batı Azerbaycan, Doğu Azerbaycan, Erdebil, Zencan, Kazvin, Hemedan bölgeleri kastedilmiştir.

16 Horasan, Türkmen ve Kaşkay değişkeleri coğrafi olarak Türklerin sayıca fazla olduğu bölgelere uzak olması sebebiyle uzak değișkeler olarak adlandırılmıștır.

17 Hemedan'ın güneyi, güneydoğusu, güneybatısı ve Sungur, Türklerin sayıca fazla olduğu bölgelerin kıyısında olması sebebiyle, kıyı değişkeleri olarak adlandırılmıștır. 
Doulatabadi, F., (2017), Kaşkay Türklerinin Edebiyat, Ankara: TDK Yayınları.

Eckmann, J., (2003), Harezm, Kipçak ve Çağatay Türkçesi Üzerine Araştırmalar, Ankara: TDK Yayınları.

Eker, S., (2008), "Türk Dili Tarihinde Bir Dilbilimsel Temas Bölgesi Olarak Diyarbakır", Osmanl'dan Cumhuriyet'e Diyarbaker, (Ed. Bahaeddin YEDIYILDIZ, Kerstin TOMENENDAL), Ankara: Diyarbakır Valiliği ve Türk Kültürünü Araştırma Enstitüsü Yayınları.

Eker, S., (2010), "Orhon Yazıtları: İran Dilleriyle İlk Temaslar ve Benzer Birkaç Öge Üzerine", III. Uluslararası Türkiyat Araştırmaları Sempozyumu, (Ed. Ülkü Çelik Şavk), C. 1, Ankara: s. 321332.

Eker, S., (2013), "İranî Diller Ailesi Genel Bir Bakış", Leyla Karahan Armağanı, Ankara: Akçă̆ Yayınları, s. 445-473.

Ersoy, F., (2016), "Çuvaş Türkçesinde Yeterlilik Kategorisi", Dil Araştırmaları, s. 85-102.

Gabain, A., V., (2007), Eski Türkçenin Grameri, Ankara: TDK Yayınları.

Gökdağ, B., A., (2006), Salmas Ağzı, Çorum: Karam Yayınları.

Gökdağ, B., A., (2016), "İran'daki Türk Dillerinde Yeterlilik Fiilinin Kullanımı", XI. Uluslararası Büyük Türk Dili Kurultayı, Budapeşte-Macaristan: İ.D. Bilkent Üniversitesi, s. 201-207.

Gülmez, G., (2008), Güney Azerbaycan Erdebil Bölgesindeki Türk Halk Masalları (Metin-İnceleme), İzmir: Ege Üniversitesi Sosyal Bilimler Enstitüsü Yayımlanmamış Yüksek Lisans Tezi.

Gün, F., (2016), Hemedanl Aşık Heyder ve Hikaye Repertuar Üzerine Bir İnceleme, Kurklareli: Kırklareli Üniversitesi Sosyal Bilimler Enstitüsü Yayımlanmamış Yüksek Lisans Tezi.

Gündüz, M., (2010), Kaşkay Atasözlerinde Ad Aktarmaları, Malatya: İnönü Üniversitesi Sosyal Bilimler Enstitüsü Yayımlanmamış Yüksek Lisans Tezi.

Johanson, L., (1998a), "Code-copying in Irano-Turkic", Language Sciences 20: 325-337.

Johanson, L., (1998b), "The History of Turkic", The Turkic Languages, London and New York: Routledge: 81-125.

Johanson, L., (2002), Structural factors in Turkic language contacts, Richmound: Surrey: Curzon Press.

Johanson, L., (2005), "Converging codes in Iranian, Semitic and Turkic", Linguistic convergence and areal diffusion. Case studies from Iranian, Semitic and Turkic, London: New York: Routledge Curzon: $3-31$.

Johanson, L. ve BULUT, C., (2006), Turkic-Iranian Contact Areas: Historical and Linguistic Aspects, Wiesbaden: Otto Harrassowitz Verlag.

Johanson, L., (2007), Türkçe Dil İlişkilerinde Yapısal Etkenler, Ankara: TDK Yayınları.

Kanar, M., (2010), Farsça-Türkçe Sözlük, İstanbul: Say Yayınları.

Karaağaç, G., (2013), Dil Bilimi Terimleri Sözlüğü, Anakara: TDK Yayınları.

Karini,. G., (2012), İran-Halhal Yöresi Türklerinin Efsaneleri Üzerine Bir İnceleme, İzmir: Ege Üniversitesi Sosyal Bilimler Enstitüsü Yayımlanmamış Doktora Tezi.

Karini, J., (2008), "Halhal Ağızlarındaki İktidari Fiilin Olumsuzunda Kullanılan -AMMA- Eki", Turkish Studies, s. 437-441.

Karini, J., (2009), Erdebil İli ve Ağızları, Ankara: Gazi Üniversitesi, Yayımlanmamış Doktora Tezi.

Kerimoğlu, C., (2011), Kiplik İncelemeleri ve Türkçe, İzmir: Dinozor Kitabevi.

Kıral, F., (2001), Das gesprochene Aserbaidschanisch von Iran: Eine Studie zu den syntaktischen Einflüssen des Persischen, Wiesbaden: Harrassowitz Verlag. 
Kural, F., (2005), "Modal Construction in Turkic of Iran", Linguistic Convergence and Areal Diffusion Case Studies from Iranian Semitic and Turkic, London and New York: RoutledgeCurzon, s. 285293.

Korkmaz, Z., (1959), "Türkiye Türkçesinde 'İktidar' ve 'İmkan' Gösteren Yardımcı Fiiller ve Gelişmeleri", TDAY-Belleten, s. 107-124.

Korkmaz, Z., (2003), Gramer Terimleri Sözlüğü, Ankaa: TDK Yayınları.

Ma'zun, (2016), Şïrler, (Haz. Muhittin ÇELİ, Gökçen DURUKOĞLU) Ankara: TDK Yayınları.

Mehmet, G., (2007), "Yeterlilik Kategorisi ve Salar Türkçesindeki Görünümü", Modern Türklük Araştırmaları Dergisi, s. 80-90.

Özdamar, F., (2015), Tebriz'de Aşılklk Geleneği ve Tebrizli Aşık Ali, Ankara: Berikan Yayınevi.

Özden, K., (2014), Şah İsmail Metni Esasında Horasan Türkçesinin Kuçan Ağzı, Muğla: Sitkı Koçman Üniversitesi Sosyal Bilimler Enstitüsü Yayımlanmamış Yüksek Lisans Tezi.

Özkaya, İ., (2013), Emsal-i Türkân, Kars: Kafkas Üniversitesi Sosyal Bilimler Enstitüsü Yayımlanmamış Yüksek Lisans Tezi.

Öztürk, M., (2007), Farsça Dilbilgisi, Ankara: Murat Kitabevi Yayınları.

Pehlivan, G., (2011), Hamedan Bölgesi Bahar Ă̆zı, İzmir: Ege Üniversitesi, Yayımlanmamış Yüksek Lisans Tezi.

Rezaei, M., (2015), İran-Zencan Bölgesi, Kaydar ve Yöresi Ağızları, Ankara: Gazi Üniversitesi Sosyal Bilimler Enstitüsü Yayımlanmamış Doktora Tezi.

Tulu, S., (2009), Horasan Türklerinden Folklor Derlemeleri (Bocnurd Ağzı), Konya: Kömen Yayınları.

Yaghoobi, V., (2011), Bir Kaşkay Türk Şiiri Antolojisi: Kaşkāì Şiłri yā Āsār-i Şu’arā-yi Kaşkāầ, Ankara: Ankara Üniversitesi Sosyal Bilimler Enstitüsü Yayımlanmamış Yüksek Lisans Tezi.

Yıldırım, Z., (2015), İran Sahası Göklen ve Nohur Türkmen Ağızları, Ankara: Ankara Üniversitesi Sosyal Bilimler Enstitüsü Yayımlanmamış Doktora Tezi.

Yüksel, Z., (2001), "Kırım Türkçesinde Ol- Yeterlik Fiili", Türk Dünyası Dil ve Edebiyat Dergisi, s. 417425 . 